International Journal of Management and Human Science

Www.ijmhs.org

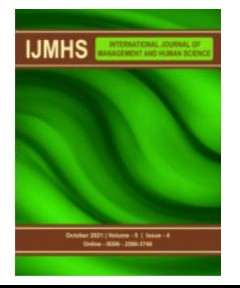

\title{
A Study on Factors Impacting the Investment in Life Insurance Policy
}

\author{
Yash Sharma*, Kausik Mukherjee, Harshvardhan Shrivastav \\ AKS University, Madhya Pradesh, India \\ *Corresponding Author’s E-Mail: yashd.sharma113@gmail.com
}

\begin{abstract}
People in India consider life insurance policy as an investment planning scheme. People are expecting safety as well as a return on investment. A Life Insurance policy is also a choice as it is also used for tax saving. Now, day by day, the insurance companies are progressing, and new companies are also emerging in this business. We have studied data for 20 investors in the insurance sector. Data is collected for Satna City. This study has been done to analyse the factors which are affecting investor's decision due to which investors incline towards insurance schemes.
\end{abstract}

Keywords: Investment Strategy, Life Insurance, Investment Inclination, Investment Perception

\section{Introduction}

When an investor tries to analyse and prioritise the scheme for Investing, insurance schemes also attracts because of many reasons (Cleartax, 2021). Few reasons are as follows:

- Insurance risk coverage

- Tax benefits availed by Investing in insurance schemes

- Return on investment

- Emotions also play important role 
There are various categories of insurance investments. The types of insurances are depicted through following chart:

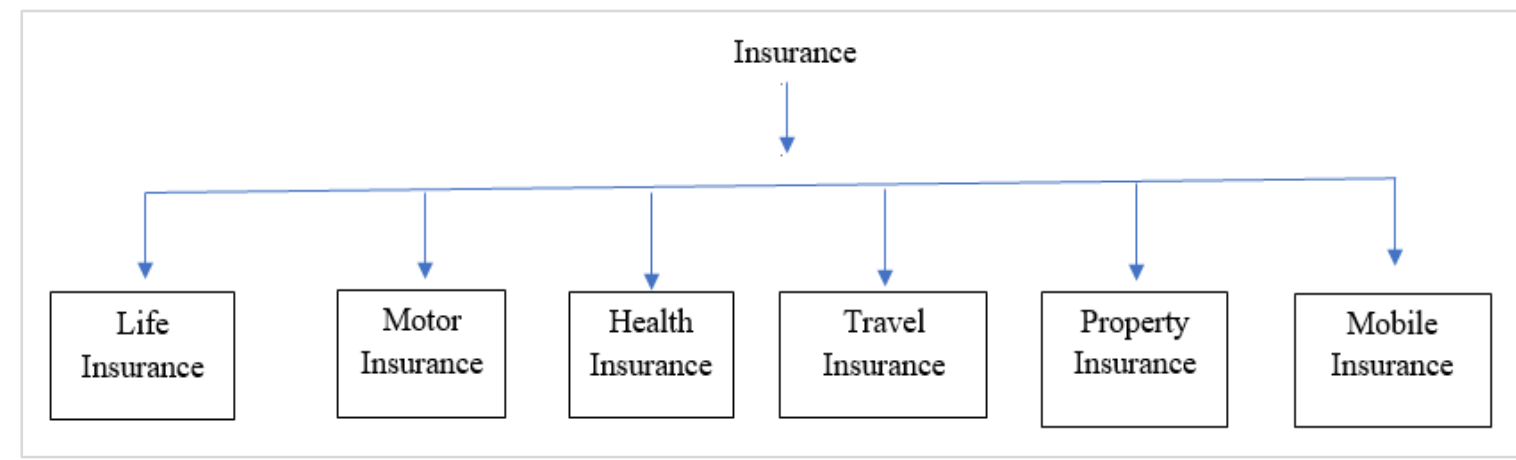

Figure 1

From the above chart, we can see that there are various types of insurances schemes where an investor can invest. Because of the above variety of insurance schemes and looking into return/ risk coverage/ tax benefits, insurance also becomes an attractive option for investors. It has been seen that among all types of insurances scheme, life insurance policy is in priority of the investors. The reason behind this is the security of the dependent family. Life insurance policy is concerned and deals with the life of the people, which is the most valuable asset in anyone's life (Beers, 2021; OECD, 2017), and in this research paper, we will talk about this paper.

Normally every individual takes at least one life insurance as it directly or indirectly takes care of left family members after the death of the investor and as an individual investor always thinks of their family security (Fontinelle, 2021). So, life insurance comes in priority of investor when he is inclined to invest in the insurance schemes.

Before investing in a life insurance policy, the investor considers many factors or in other words, there are many factors that influence the decision. There are middle-class people and salaried people who think more for return (Maheswari, 2020). In this paper, we will throw light on all these factors.

\section{Objective of the Study}

- To evaluate the factors influencing the investment in life insurance policy

- To understand the preference of customer among various insurance schemes while taking life insurance policy

- To study and rank factors responsible for selection of life insurance as an investment option

- To suggest for the increase of the trend of taking life insurance by maximum people 


\section{Research Methodology}

- This research is empirical in nature

- The data were collected from secondary sources

- Sampling universe is the people of Satna city

- Judgement sampling was used for selection of samples

- Sample size was any random 20 people

\section{Analysis}

Under this research we have taken the samples of 20 people who have invested in following plans:

- Endowment Plan

- Child Plan

- Money back plan

- Term Plan

- ULIP Plan

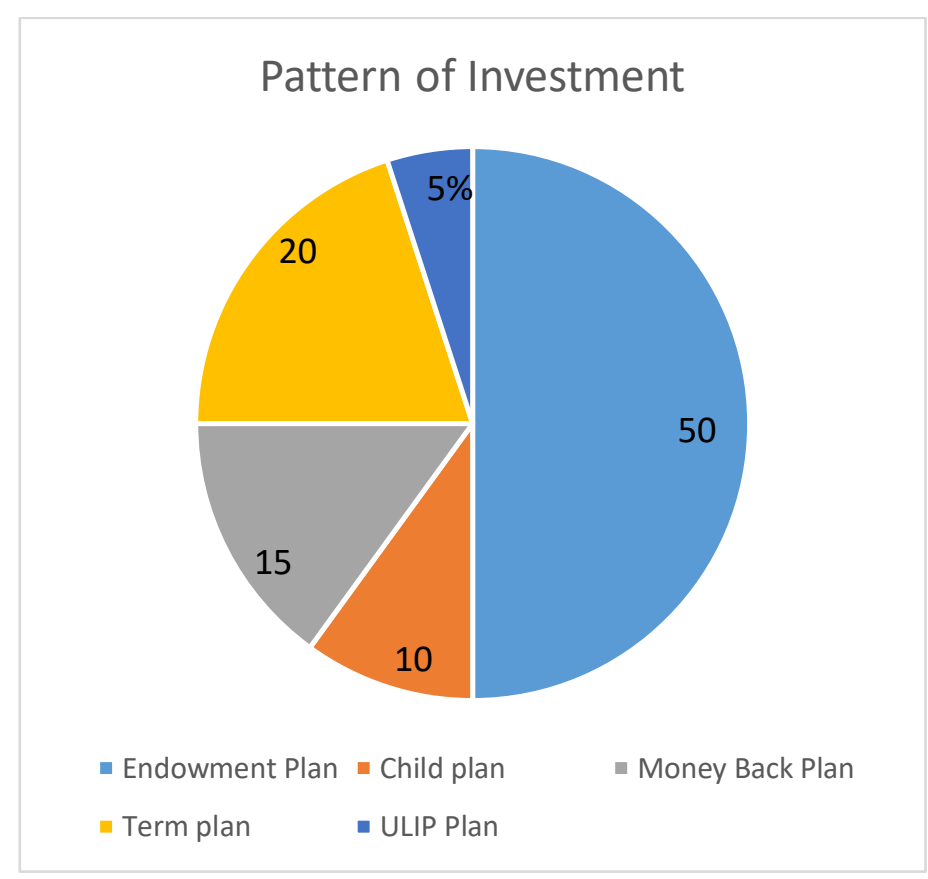

Figure 2

In the above graph, we can see that $50 \%$ of the population has taken endowment policy, $20 \%$ has taken term plan, $15 \%$ has taken money back plan, $10 \%$ has taken child plan whereas $5 \%$ has taken ULIP Plan.

This also shows that the majority of the people are interested in getting a covered amount plus bonus on maturity and a second large percentage of people take term insurance even if they are not getting anything on maturity. 
We also get to understand the thinking pattern of the people through the above sample of 20 people which reflects the below analysis.

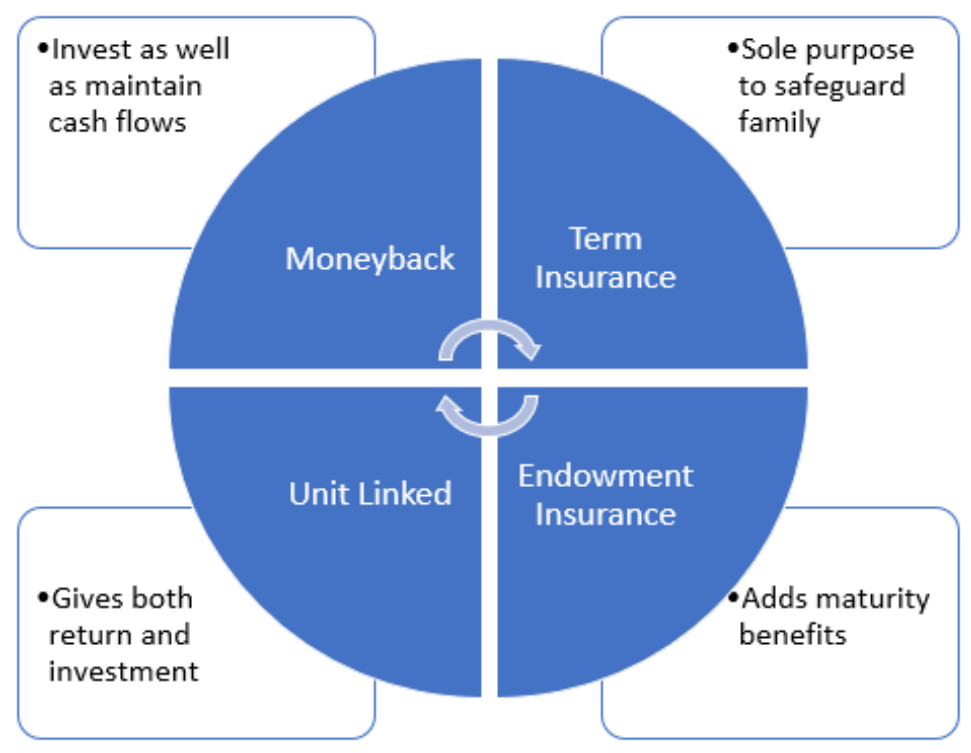

\section{Figure 3}

From the above graph, we can see that the priorities of investors vary depending upon various factors. From the graph given below, we may see that what are factors that have an impact on taking investment decisions.

Factors Impacting the Investment Decision

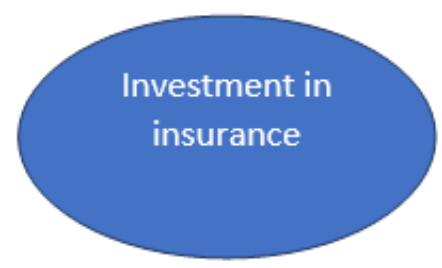

$$
\text { Return }
$$

High risk coverage

Premium

\section{Figure 4}

- Premium: Premium should be very competitive in today's scenario as the expectation of most of the people is to get high coverage in less premium

- Risk over: High risk cover also attracts the investor

- Return: In today's world everyone has investment point of even in the insurance policy, so money back is also important factor to invest in insurance. 


\section{Conclusion}

We can visualize that as our country is developing and sources of Income are also increasing. Investor inclination towards life insurance policy is increasing. The most important factors that impact the decision of an investor are premium, risk cover, return, money back and return on investment. Further, there is a lot of scope of growth of investment in the life insurance policy, but insurance companies are required to increase advertisement and more awareness is required to be spread among the people. Declaration of incentive policy may further enhance the business of the insurance companies.

\section{Conflict of Interest}

The authors declare that they have no conflict of interest.

\section{Acknowledgement}

The authors are thankful to the institutional authority for completion of the work.

\section{References}

Beers, B. (2021, June 17). Life Insurance: Putting a Price on Peace of Mind. Investopedia. https://www.investopedia.com/articles/pf/05/012405.asp

Cleartax. (2021). Investments in India: Why Investing is Important \& Where to Invest?. https://cleartax.in/s/investments

Fontinelle, A. (2021, October 18). Life Insurance Guide to Policies and Companies. Investopedia. https://www.investopedia.com/terms/l/lifeinsurance.asp

Maheswari, Y. (2020). A Comparative Study on Performance of Selected Mutual Funds in India.

https://deliverypdf.ssrn.com/delivery.php?ID=99708500400609312412611409109911012502 606400204005207407808806509010209002610209609212102203811811401411608111808 808100402901802802000405304801402511907008102209410300202800111509301301411 $4025091126006125001086125093101104007093080117024092070127088116 \& E X T=$ pdf $\&$ INDEX=TRUE

Organisation for Economic Co-operation and Development (OECD). (2017). Investment governance and the integration of environmental, social and governance factors. https://www.oecd.org/finance/Investment-Governance-Integration-ESG-Factors.pdf 